\title{
Inhibition of Ophiognomonia clavigignenti-juglandacearum by Juglans Species Bark Extracts
}

M. J. Moore and M. E. Ostry, Northern Research Station, USDA Forest Service, St. Paul, MN; and A. D. Hegeman and A. C. Martin, Department of Horticulture, University of Minnesota, St. Paul

\begin{abstract}
Moore, M. J., Ostry, M. E., Hegeman, A. D., and Martin, A. C. 2015. Inhibition of Ophiognomonia clavigignenti-juglandacearum by Juglans species bark extracts. Plant Dis. 99:401-408.

A rapid and reliable technique is needed for identifying butternut trees (Juglans cinerea) with resistance to butternut canker. We investigated the potential of a bark extract bioassay to detect levels of resistance to Ophiognomonia clavigignenti-juglandacearum $(O c-j)$, the causal agent of butternut canker. Both reagent grade naphthoquinones and crude bark extracts of Juglans species inhibited germination of $O c-j$ conidia. A disc diffusion bioassay was used to study the level of inhibition by these bark extracts and results indicated extensive variation within and between butternut and other species of Juglans tested. In many months over a 3 year period, bark from butternut trees selected for apparent disease resistance could be distinguished from that of unselected trees. Inhibition of conidia germination roughly correlated to the level of

resistance observed in field inoculations of the trees. Quantification of the naphthoquinone compounds juglone and plumbagin in butternut bark was performed using ultra-high performance liquid chromatography mass spectrometry. While the concentrations of these two compounds varied by month and by individual tree, juglone levels correlated well with the bark extract bioassay in some months. These results suggest that juglone concentration may account in part for the observed range of inhibition observed in the bioassay and variation in canker resistance among selections of butternut field inoculated with $O c-j$. The bark extract bioassay described in the following report may have potential use for selecting resistant butternut for conservation and restoration purposes.
\end{abstract}

Butternut (Juglans cinerea) is being killed throughout North America by butternut canker caused by Ophiognomonia clavigignenti-juglandacearum (Oc-j) (=Sirococcus clavigignentijuglandacearum) (5). Since the first report of the disease in 1967 (1), researchers in the United States and Canada have investigated the potential conservation of individual trees that may have resistance to the disease. Occasionally, one to several healthy butternut trees have been found growing among groups of similarly aged diseased and dying butternut. These trees may exhibit some form of resistance to the disease, and a number of these selections have been grafted and grown in research plantings and may have value for breeding and restoration of the species (21).

Variation in susceptibility to $O c-j$ among Juglans species and butternut selected for potential resistance has been demonstrated using artificial wound inoculation tests in the field $(25,27)$. Heartnut (Juglans ailantifolia var. cordiformis) and black walnut (J. nigra) were among the least susceptible, and Persian walnut $(J$. regia) was the most susceptible among the species tested. Inoculations of putative resistant butternuts revealed significant differences between accession, month of inoculation, and fungal isolate (27). Resistance mechanisms to $O c-j$ among different Juglans species have been only minimally explored. It has widely been observed that butternut $\times$ heartnut hybrids, often referred to as "buarts," are more resistant to the canker disease than pure butternuts (15). Nair (22) hypothesized that the thicker periderm of heartnut and the high phenolic content of black walnut bark confers disease resistance to those species.

\section{Corresponding author: M. J. Moore, E-mail: melaniemoore@fs.fed.us}

* The $e$-Xtra logo stands for "electronic extra" and indicates that two supplementary figures are available online.

Accepted for publication 16 September 2014.

http://dx.doi.org/10.1094/PDIS-06-14-0642-RE

This article is in the public domain and not copyrightable. It may be freely reprinted with customary crediting of the source. The American Phytopathological Society, 2015.
The secondary metabolites (often phenolic compounds) produced by trees involved in resistance to pathogens have been extensively studied. Some of these substances are present in the tissues at constitutive levels, and others are induced by wounding or the presence of a pathogen. Researchers have often found a correlation between higher levels of constitutive phenolics and higher levels of disease resistance. For example, willow with higher levels of secondary phenolics was found to be more resistant to leaf rust (13). Baiocchi et al. (2) found varying levels of phenolics among poplars relating to different levels of resistance to Discosporium populeum. Lieutier et al. (18) found that constitutive phloem phenolics in Norway spruce correlated to a higher resistance to Ceratocystis polonica. In this case, the diversity of phenolics was a key factor. Others have found seasonal variation in levels of phenolic compounds important. For example, Solar et al. (31) found that seasonal fluctuations of naphthoquinones and phenolic acids in walnut shoots and fruits may account for seasonally variable resistance to bacterial blight.

There is evidence that substances in butternut bark have substantial fungicidal and antimicrobial properties. Butternut bark extracts were the most antagonistic and had the broadest spectrum of activity of the tree species tested against several human pathogenic bacteria (9) and several fungi (24). It is probable that these substances are a part of the tree's defense mechanisms against disease.

It is generally established that Juglans species contain a number of structurally related, polycyclic compounds called naphthoquinones. Several naphthoquinones known to be present in J. regia husks including 1,4-naphthoquinone, juglone, menadione, and plumbagin were found to inhibit Aspergillis flavis in culture and reduced aflatoxin production (19). Naphthoquinones also inhibited the growth of several human pathogenic bacteria $(23,28,29)$.

The most thoroughly studied naphthoquinone in Juglans species is juglone. It has long been observed that walnut trees are detrimental to the growth of certain nearby plants such as alfalfa, apples, and tomatoes. Root exudates containing juglone were implicated in this allelopathic effect $(8,20)$. Juglone is present in the roots, leaves, fruit hulls, and bark of black walnut and butternut (12). Pure juglone and crude extracts from green walnut hulls have been found to inhibit the growth of a wide range of microorgan- 
isms including bacteria, filamentous bacteria, algae, and dermatophytes (17), and juglone was an effective inhibitor of Botrytis cinerea, Cladosporium herbarum, and Fusarium avenaceum growth (10). Inhibition of the growth of the wood-rotting fungus Pleurotus sajor-caju (7) and the pecan scab fungus, Fusicladium effusum (33) by juglone has also been demonstrated. It has been suggested that the high levels of juglone in black walnut leaves may be responsible for its greater resistance to scab than that observed in pecan (11).

In a study of black walnut, juglone was more effective in inhibiting growth of non-pathogens (Gnomonia quercina, G. platani, and Sclerotinia sclerotiorum) and one pathogen (Cristulariella moricola) than against two other pathogens, Cylindrosporium juglandis and Gnomonia leptostyla (6). This may indicate an evolved tolerance to juglone among some Juglans pathogens, and a higher concentration of juglone may be required to inhibit their growth. In this study, juglone concentration variation was related to leaf age, with young leaves having a higher juglone concentration and being more resistant to anthracnose fungi than older leaves.

Other naphthoquinones have been found to be produced by $\mathrm{Ju}$ glans species. Binder et al. (4) extracted 1,4-naphthoquione, plumbagin, and menadione from the unripe hulls of J. nigra and $J$. regia. To date, no other naphthoquinones other than juglone have been described in J. cinerea.

This paper provides results of our test of reagent grade naphthoquinones and crude bark extracts of Juglans species and a Juglans hybrid for their effects on $O c-j$ conidia germination using a disc diffusion bioassay. Bark extracts were also analyzed to determine naphthoquinone content. The objectives of this research were to determine a possible resistance mechanism in butternut to infection by $O c-j$ and to develop a technique to select for resistance among trees. The hypothesis was two-fold; first, that a disc diffusion bioassay using bark extracts from butternut selections could distinguish differences in levels of $O c-j$ conidial germination inhibition; second, that butternut bark from different selections differed in napthoquinone concentration, and that these differences were correlated with the level of inhibition detected in the bioassay.

\section{Materials and Methods}

Fungal cultures. Cultures of $O c-j$ isolated from butternut cankers were grown on $3 \%$ malt agar in petri plates at $20^{\circ} \mathrm{C}$ in the dark until sporulation occurred (usually 15 to 30 days). Sporulating cultures were flooded with sterile deionized water and rubbed lightly with a sterile, bent plastic rod to dislodge conidia. Suspensions were vortexed, and any agar and mycelia fragments were allowed to settle out. The suspension was adjusted to $4 \times 10^{5} O c-j$ conidia per $100 \mu \mathrm{l}$ with sterile deionized water using a hemacytometer. Conidia from two different isolates, one each from Wisconsin and Minnesota, were separately used in the bark extract assays in 2006. A mixture of conidia obtained from two isolates collected in Wisconsin and two from Minnesota was used in the naphthoquinone assay and in the bark extract assays in 2010 and 2011.

Disc diffusion bioassay with reagent grade naphthoquinones. The disc diffusion bioassay procedure used was similar to standard antibiotic sensitivity tests (3), and was conducted using several related naphthoquinones to determine their activity against $O c-j$. The naphthoquinones tested included juglone, 1,4-naphthoquinone, plumbagin, menadione, and lawsone; all were obtained from Sigma-Aldrich (St. Louis, MO). The naphthoquinones were dissolved in $95 \%$ ethanol and applied to sterile $6.5 \mathrm{~mm}$ diameter cellulose discs at a rate of 5, 10, 20, 50, and $100 \mu \mathrm{g}$ per disc. A $95 \%$ ethanol control was also prepared. A suspension of $4 \times 10^{5} O c-j$ conidia was applied to $100 \mathrm{~mm}$ petri dishes containing $3 \%$ malt agar and spread evenly with a sterile bent rod. One disc of each naphthoquinone concentration was applied to the center of each plate and eight replicate discs of each naphthoquinone were tested for each treatment level. Plates were placed in the dark and incubated at $20^{\circ} \mathrm{C}$ for $72 \mathrm{~h}$.

After incubation, fungal growth was visible on the plates as a solid lawn, except for a clear inhibition zone around the discs. The diameter of each of these inhibition zones (including the disc) was measured to the nearest $0.5 \mathrm{~mm}$ using a circular template, and samples with no inhibition were recorded as $6.5 \mathrm{~mm}$ (the diameter of the disc). The entire experiment was repeated.

Plant material. All bark samples were collected from a plantation near Rosemount, MN, consisting of trees planted from 1994 to 1996. Species included J. cinerea, J. nigra, J. ailantifolia var. cordiformis, and the hybrid J. cinerea $\times J$. ailantifolia. The $J$. cinerea trees included both seedling butternut of unknown origin ("unselected") and grafted trees propagated from putative resistant disease-free trees growing among severely diseased trees ("selected") (Table 1). Eleven of these selected trees had been used in a previous field inoculation study (27), and none of the unselected trees had been previously inoculated.

Bark samples were collected from 10 trees in 2006 and 15 (the same trees as 2006 plus five additional selected trees) in 2010. In 2011, bark samples were collected from 69 trees, including the 15 trees used previously. The trees included 10 unselected seedling butternuts, two seedling black walnut, three grafted hybrids, one grafted heartnut, and 53 grafted butternuts. The grafted trees included those selected for possible disease resistance (42 trees) and a collection of named varieties selected in the past for good nut characteristics but not for disease resistance (11 trees). The majority of these named varieties were susceptible to butternut canker (26). A minimum of three $30 \mathrm{~cm}$ lengths $(0.5$ to $2.5 \mathrm{~cm}$ diameter) of 4- to 6-year-old branches per tree were collected each month. Branches were collected from different sides of each tree and kept at $4^{\circ} \mathrm{C}$ until they were peeled, within 1 to 2 weeks after collection.

Bark extraction. In 2006, branches were collected mid-month from April through October. Bark tissue was divided by age: current year (greenwood), 1- to 2-year-old, and 3- to 4-year-old. Based on preliminary studies in which the outer bark was found to be less inhibitory, the outer (green layer) bark was discarded and only the inner, fibrous bark was used. Current-year bark was collected starting in June. Removal of outer bark was not practical for samples of current year bark. The following extraction procedure was according to Omar et al. (24). Bark was air-dried and ground in a Wiley mill to a fineness of a 20 mesh screen $(0.8 \mathrm{~mm})$. For the extraction, the bark powder was soaked in $95 \%$ ethanol at a rate of $3 \mathrm{~g}$ per $15 \mathrm{ml}$ for $48 \mathrm{~h}$ with occasional agitation and then filtered (Whatman \#1, Maidstone, England) and air dried. A total of 190 extract samples from 10 trees (Table 1) were prepared and stored at $-20^{\circ} \mathrm{C}$. Extracts from each collection were prepared once and two bioassay experiments were carried out on each sample of the extract.

In 2010 and 2011, the inner bark of 1- to 6-year-old branches was used. The extraction procedure was modified somewhat to reduce heating and oxidative processes during grinding and to increase yield. Bark was ground with dry ice and stored at $-70^{\circ} \mathrm{C}$. The extraction process was started by mixing $1 \mathrm{~g}$ of bark powder in $10 \mathrm{ml}$ of cold $\left(-20^{\circ} \mathrm{C}\right) 95 \%$ ethanol and soaking the mixture overnight at $-20^{\circ} \mathrm{C}$. Mixtures were then agitated at room temperature for $24 \mathrm{~h}$, centrifuged, and the supernatant removed. Two successive extractions of $10 \mathrm{ml}$ of $95 \%$ ethanol each were performed on the same bark powder and added to the original aliquot for a total of 30 $\mathrm{ml}$ of combined extract. Extracts were evaporated under vacuum to near dryness, and then air-dried to a tarry consistency.

Bark samples were generally collected the third week of each month from April to October in 2010. A total of 105 samples from 15 trees (Table 1) were prepared, stored at $-70^{\circ} \mathrm{C}$, and three bioassay experiments were carried out on each sample. In 2011, bark samples were collected on May 25 and August 16 from 68 and 69 trees, respectively. The same extraction procedures, number of experiments, and chemical analysis were used as in 2010.

Disc diffusion bioassay with bark extracts. Bark extracts were re-suspended in $95 \%$ ethanol and applied to sterile $6.5 \mathrm{~mm}$ cellulose discs at a rate of $2 \mathrm{mg}$ per disc, then air dried. Ethanol controls were also prepared. To each $3 \%$ malt agar $100 \mathrm{~mm}$ petri plate, a suspension of $4 \times 10^{5} O c-j$ conidia was spread over the surface 
Table 1. Trees used for bark extraction in 2006, 2010, and 2011; unless otherwise noted, trees were grafted onto Juglans nigra rootstock, and all trees were growing in Rosemount, MN, and planted 1994-1996

\begin{tabular}{|c|c|c|c|c|c|}
\hline Accession $^{x}$ & 2006 & 2010 & 2011 & Species/variety & Original location \\
\hline B03 & $\mathrm{X}$ & $\mathrm{X}$ & $X$ & J. cinerea seedling & Unknown \\
\hline B04 & $X$ & $\mathrm{X}$ & $X$ & J. cinerea seedling & Unknown \\
\hline B05 & & & $X$ & J. cinerea seedling & Unknown \\
\hline B06 & & & $X$ & J. cinerea seedling & Unknown \\
\hline B07 & & & $X$ & J. cinerea seedling & Unknown \\
\hline B08 & & & $X$ & J. cinerea seedling & Unknown \\
\hline B09 & & & $X$ & J. cinerea seedling & Unknown \\
\hline B10 & $X$ & $X$ & $X$ & J. cinerea seedling & Unknown \\
\hline B11 & $X$ & $\mathrm{X}$ & $\mathrm{X}$ & J. cinerea seedling & Unknown \\
\hline B16 & $\mathrm{X}$ & $\mathrm{X}$ & $\mathrm{X}$ & J. cinerea seedling & Unknown \\
\hline $\mathrm{S} 01^{\mathrm{y}}$ & & $\mathrm{X}$ & $X$ & J. cinerea & Dunn Co., WI \\
\hline S06 & & & $X$ & J. cinerea & Caledonia, MN \\
\hline $\mathrm{S} 10$ & & & $\mathrm{X}$ & J. cinerea & Arlington, WI \\
\hline S19y & & & $X$ & J. cinerea & Olmstead Co., MN \\
\hline S20y & & $X$ & $X$ & J. cinerea & Whitewater, WI \\
\hline $\mathrm{S} 22^{\mathrm{y}}$ & $X$ & $X$ & $X$ & J. cinerea & Whitewater, WI \\
\hline $\mathrm{S} 23^{\mathrm{y}}$ & & & $X$ & J. cinerea & Whitewater, WI \\
\hline $\mathrm{S} 28$ & & & $X$ & J. cinerea & Red Wing, MN \\
\hline S36 & & & $X$ & J. cinerea & Trade Lake, WI \\
\hline S37 & & & $X$ & J. cinerea & Trade Lake, WI \\
\hline S38 & & & $\mathrm{X}$ & J. cinerea & Trade Lake, WI \\
\hline S39 & & & $\mathrm{X}^{\mathrm{z}}$ & J. cinerea & Trade Lake, WI \\
\hline S5 $54^{y}$ & & $X$ & $\mathrm{X}$ & J. cinerea & Nicolet NF, WI \\
\hline S55 & & & $X$ & J. cinerea & Nicolet NF, WI \\
\hline S60y & & $\mathrm{X}$ & $\mathrm{X}$ & J. cinerea & Whitewater, WI \\
\hline S61 & & & $X$ & J. cinerea & Whitewater, WI \\
\hline S67y & & $X$ & $X$ & J. cinerea & Mazaska Lake, MN \\
\hline S69 & & & $X$ & J. cinerea & Plymouth, MN \\
\hline S71 & & & $X$ & J. cinerea & Trade Lake, WI \\
\hline S78 & & & $X$ & J. cinerea & Rochester, MN \\
\hline S83 & & & $X$ & J. cinerea & Mark Twain NF, MO \\
\hline $\mathrm{S} 86^{\mathrm{y}}$ & & & $X$ & J. cinerea & Mark Twain NF, MO \\
\hline S87 & & & $\mathrm{X}$ & J. cinerea & Mark Twain NF, MO \\
\hline S95 & & & $\mathrm{X}$ & J. cinerea & Perch River, NY \\
\hline S96 & & & $X$ & J. cinerea & Perch River, NY \\
\hline S97 & & & $X$ & J. cinerea & Perch River, NY \\
\hline S109 & & & $X$ & J. cinerea & Charlotte, MI \\
\hline $\mathrm{S} 132$ & & & $X$ & J. cinerea & Berlin, VT \\
\hline $\mathrm{S} 134$ & & & $X$ & J. cinerea & Berlin, VT \\
\hline $\mathrm{S} 135$ & & & $\mathrm{X}$ & J. cinerea & Berlin, VT \\
\hline S136 & & & $X$ & J. cinerea & Williston, VT \\
\hline $\mathrm{S} 140$ & & & $\mathrm{X}$ & J. cinerea & Red Wing, MN \\
\hline $\mathrm{S} 140$ & & & $X$ & J. cinerea & Red Wing, MN \\
\hline S141 & & & $X$ & J. cinerea & Trade Lake, WI \\
\hline $\mathrm{S} 143$ & & & $\mathrm{X}$ & J. cinerea & Raddison, WI \\
\hline S144 & & & $X$ & J. cinerea & Nicolet NF, WI \\
\hline $\mathrm{S} 146^{\mathrm{y}}$ & & & $X$ & J. cinerea & Whitewater, WI \\
\hline S147 & & & $X$ & J. cinerea & Whitewater, WI \\
\hline S148 & $X$ & $\mathrm{X}$ & $\mathrm{X}$ & J. cinerea & Whitewater, WI \\
\hline S153 & & & $X$ & J. cinerea & Daniel Boone NF, KY \\
\hline S173 & & & $X$ & J. cinerea & Isanti Co., MN \\
\hline S180 & & & $X$ & J. cinerea & Chalk Hills, MI \\
\hline S188 & & & $X$ & J. cinerea & Polk City, IA \\
\hline N154 & & & $X$ & J. cinerea 'Montauk' & MO \\
\hline N155 & & & $\mathrm{X}$ & J. cinerea 'Kinneyglen' & NY \\
\hline N156 & & & $\mathrm{X}$ & J. cinerea 'Weschcke' & IA \\
\hline N157 & & & $\mathrm{X}$ & J. cinerea 'Creighton' & PA \\
\hline N158 & & & $X$ & J. cinerea 'Painter' & PA \\
\hline N160 & & & $X$ & J. cinerea 'Ayres' & MI \\
\hline N161 & & & $X$ & J. cinerea 'George Elmer' & NY \\
\hline N162 & & & $X$ & J. cinerea 'Ft. Wood A' & MO \\
\hline N164 & & & $\mathrm{X}$ & J. cinerea 'Bear Creek' & IA \\
\hline N167 & & & $\mathrm{X}$ & J. cinerea 'New Discovery' & $\mathrm{MN}$ \\
\hline N169 & & & $\mathrm{X}$ & J. cinerea 'Booth' & NY \\
\hline H133 & $\mathrm{X}$ & $\mathrm{X}$ & $\mathrm{X}$ & J. ailantifolia var. cordiformis & Berlin, VT \\
\hline Y92 & & & $\mathrm{X}$ & Probable $J$. cinerea $\times J$. ailantifolia & Loudon, NH \\
\hline Y128 & $\mathrm{X}$ & $\mathrm{X}$ & $\mathrm{X}$ & $J$. cinerea $\times J$. ailantifolia & Sanford, ME \\
\hline Y165 & & & $\mathrm{X}$ & $J$. cinerea $\times J$. ailantifolia 'Mitchell' & MI \\
\hline W01 & $\mathrm{X}$ & $\mathrm{X}$ & $\mathrm{X}$ & J. nigra seedling & Unknown \\
\hline W02 & & & $X$ & J. nigra seedling & Unknown \\
\hline
\end{tabular}

${ }^{\mathrm{x}}$ Group designators are as follows: $\mathrm{B}$, unselected butternut; $\mathrm{S}$, selected (putative resistant) butternut; N, named butternut variety; H, heartnut; Y, hybrid; W, black walnut.

$\mathrm{y}$ Tree used in previous field inoculation study (27).

z S39 was used only in August 2011. 
evenly using a sterile, bent rod. Four discs of each extract were placed equidistant on each malt agar plate, with two replicate plates for each combination of month, accession, and in 2006, isolate and bark age. Plates were incubated at $20^{\circ} \mathrm{C}$ in the dark for $72 \mathrm{~h}$. Following incubation, inhibition zone diameter was measured to the nearest $0.5 \mathrm{~mm}$ using a circular template.

Chemical analysis. The same extracts used for the bioassay were used for the chemical analysis. For each extract, $20 \mathrm{mg}$ was dissolved in $200 \mu \mathrm{l}$ of $20 \%$ acetonitrile in water with $0.1 \%$ formic acid. The mixture was sonicated and filtered using Nanosep MF 0.2 micron spin filters (Pall Life Sciences, Ann Arbor, MI) to remove fine particles. Solutions of known naphthoquinones used for the first bioassay were used for comparison for component identification in 2006. Later analyses used a standard curve of known concentrations of only juglone and plumbagin. Samples were analyzed by reversed-phase ultra-high performance liquid chromatography-mass spectrometry (UPLC-MS) using a Waters $\mathrm{C}_{18} \mathrm{BEH}$ column, UPLC and SQD MS detector in negative electrospray ionization mode (Waters Corp., Milford, MA). The samples were separated on a water-acetonitrile gradient from 20 to $98 \%$ acetonitrile over $11 \mathrm{~min}$.

Standard naphthoquinones were used to identify the compounds by matching elution time and mass to confirm their presence or absence in each extract. Standard curves for juglone and plumbagin were used to determine their concentration by integrated peak area for extracts collected in 2010 and 2011. A linear regression equation was produced for the best fit in the range of areas found for the extracts.

Each extract was analyzed three times, and peak areas were determined for juglone and plumbagin by integrating over the same time period for each peak using MassLynx software (Waters). This area was transformed by the regression equation into millimolar concentration, which was used as the quantification or dependent variable for all related statistics.

Statistical analysis. All bioassay experiments were a completely randomized design, with blocking for tissue age and isolate in 2006. In 2006, because preliminary ANOVA analysis revealed extracts from the current year's branch growth had significantly less inhibitory effect, those data were disregarded and data from 1to 4-year-old branch growth combined in the final analysis. Inhibition zone data points were based on the mean of eight measurements per accession per month. These mean inhibition zones were the dependent variables and were subjected to analysis by mixed model ANOVA (Enterprise Guide 4.2, SAS Institute, Cary, NC). Tree accession, species/selection, and month of collection were included as fixed effects and tissue age and isolate were included as random effects. Juglone and plumbagin concentrations were subjected to one-way ANOVA. Least square means separation tests were conducted using a Fisher's Least Squares Difference procedure with a significance level of 0.05 .

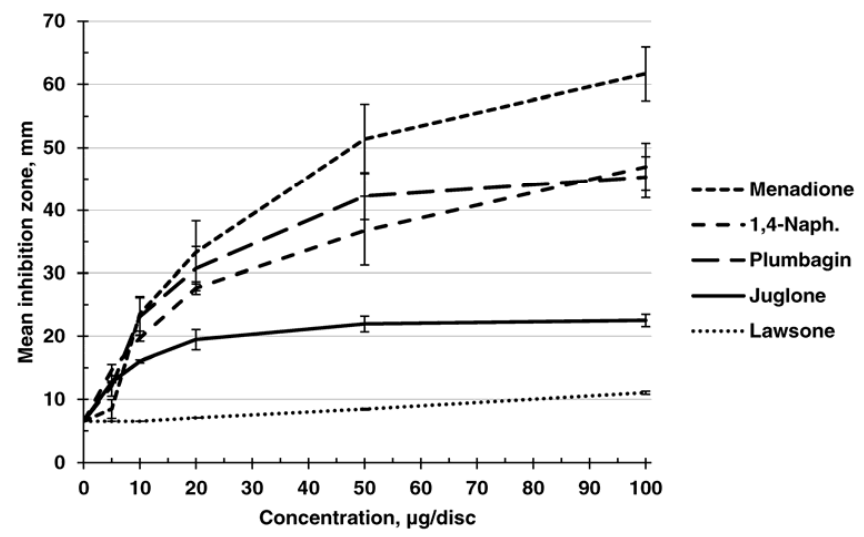

Fig. 1. Inhibition of Oc-j conidia germination by reagent grade naphthoquinones using a disc assay after $72 \mathrm{~h}$. Data points are mean diameters of inhibition zones of eight discs and two replications. Bars are standard error.
We used linear regression analysis to evaluate the effects of juglone and plumbagin concentration (independent variables) on mean inhibition zone size (dependent variable).

\section{Results}

Inhibition of Oc-j conidia by reagent grade naphthoquinones. Inhibition of $O c-j$ conidia germination varied by naphthoquinone (Fig. 1). Menadione, 1,4-naphthoquinone, and plumbagin were highly inhibitory, with mean inhibition zones of 62,47 , and $45 \mathrm{~mm}$, respectively, at a concentration of $100 \mu \mathrm{g}$ per disc. Juglone was also inhibitory, but to a lesser extent, with a mean inhibition zone of $23 \mathrm{~mm}$ at $100 \mu \mathrm{g}$ per disc. Lawsone was minimally inhibitory, $11 \mathrm{~mm}$ at $100 \mu \mathrm{g}$, and the ethanol controls exhibited no inhibition.

Inhibition of $\boldsymbol{O c}-\boldsymbol{j}$ by bark extracts. Comparison of bark age and isolate. Bark extracts from the current year's growth in 2006 had a significantly $(P<0.0001)$ weaker inhibitory effect than extracts from older bark. The inhibitory effect of extracts from 1- to 2-year-old bark were not significantly different from extracts of the 3 - to 4 - year-old bark $(P=0.99)$. The level of inhibition in the first replication was consistently greater than in the second replication $(P<0.0001)$. However, the difference had no effect on the ranking of the accessions in the experiments (data not shown). The level of inhibition varied by $O c-j$ isolate. Isolate, however, had no effect on the ranking of the accessions (data not shown).

Comparison of collection month. In 2006 and 2010, the inhibition zone varied significantly $(P<0.0001)$ by month of bark collection (Fig. 2). In 2006, inhibition peaked with May collections and the least inhibition was obtained in June and October. The level of inhibition of extracts from bark collections in August and September were not significantly different from each other $(P=$ 0.99). In 2010, there was no May peak, with a late summer peak relatively larger than spring. As in 2006, extracts collected in August and September of 2010 were not significantly different from each other. In 2011, bark was collected in only two months, and the mean inhibition zone was significantly larger $(P<0.0001)$ in $\mathrm{Au}-$ gust $(19.0 \mathrm{~mm})$ than in May $(17.4 \mathrm{~mm})$.

Comparison of selection and species. In 2006, extracts from selected butternuts produced significantly larger inhibition zones $(P$ $<0.0001)$ than extracts from the unselected butternuts in every month but July (Fig. 3). The greatest mean differences between the groups occurred with collections in September, April, and August with mean differences of 3.0, 2.9, and $2.8 \mathrm{~mm}$, respectively. Inhibition by the extracts from black walnut, heartnut, and butternut $x$ heartnut hybrid also varied from month to month (Fig. 4). Each of these species was represented by only one tree, while the unselected and selected trees were a mean of five and two trees, respectively.

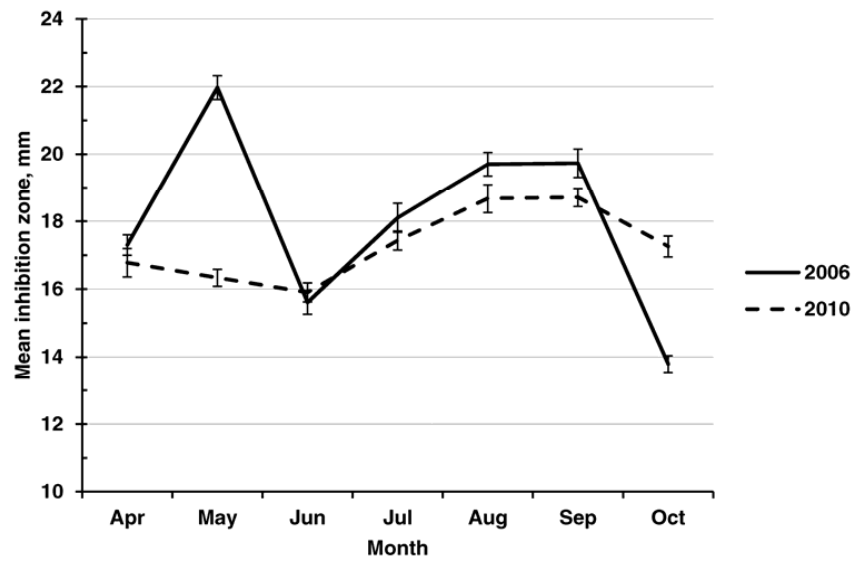

Fig. 2. Inhibition of $\mathrm{Oc}-j$ conidia germination at $72 \mathrm{~h}$ using a bark extract disc assay, comparing experimental year and month of bark collection. Data points are mean diameters of inhibition zones for all accessions combined. The experiment had two replications in 2006 and three replications in 2010. Bars represent standard error. 
In 2010, the differences in mean inhibition zones among sources were most clearly evident using the extracts from the August bark collection (Fig. 4). While bark extracts from all accessions yielded peak inhibition in late summer or early fall, the inhibition effect of extracts from the selected butternuts peaked earlier and were greater (August) than the unselected butternuts (September). The mean separation was found to be significant for unselected versus selected for every month but September and October (Fig. 3). The August mean separation was $4.6 \mathrm{~mm}$, followed by July and April, at 2.6 and $2.1 \mathrm{~mm}$, respectively. Inhibition by extracts from walnut, heartnut, and hybrid were still variable, but less than in 2006 (Fig. 4).

In 2011, the difference between selected and unselected butternuts was only significant in August (Fig. 5). The named varieties were indistinguishable from either the selected or unselected group. Significant differences were found in individual accessions in both May and August and the accessions ranked in broadly overlapping groups (Supplementary Figure 1).

Comparison of accession in August. The most consistent mean separation over the three years between bark extracts of selected and unselected butternut was with the August bark extracts. For some trees, the relative ranking by the relative size of inhibition zones was consistent from year to year (Table 2). For example, inhibition zones by extracts of B16 consistently ranked as the smallest in all three years, and B03 ranked moderately small. Inhibition zones of bark extracts from S22 were larger than all other accessions in 2006 and continued to rank among the largest in 2010 and 2011. Inhibition zones of extracts of S67 were large for both of the years it was used (2010 and 2011). Extracts from the hybrid (Y128) varied little, from moderate to relatively large inhibition zones. Inhibition by extracts from some accessions were more variable, such as B04 that had moderately small inhibition zones in 2006 and 2010 but large ones in 2011. Both the walnut and the heartnut extracts yielded inhibition zones that were also somewhat variable, ranking moderate to small depending on year.

Chemical analysis. Identification and quantification of naphthoquinones. Peaks that were observed via UPLC-MS matched
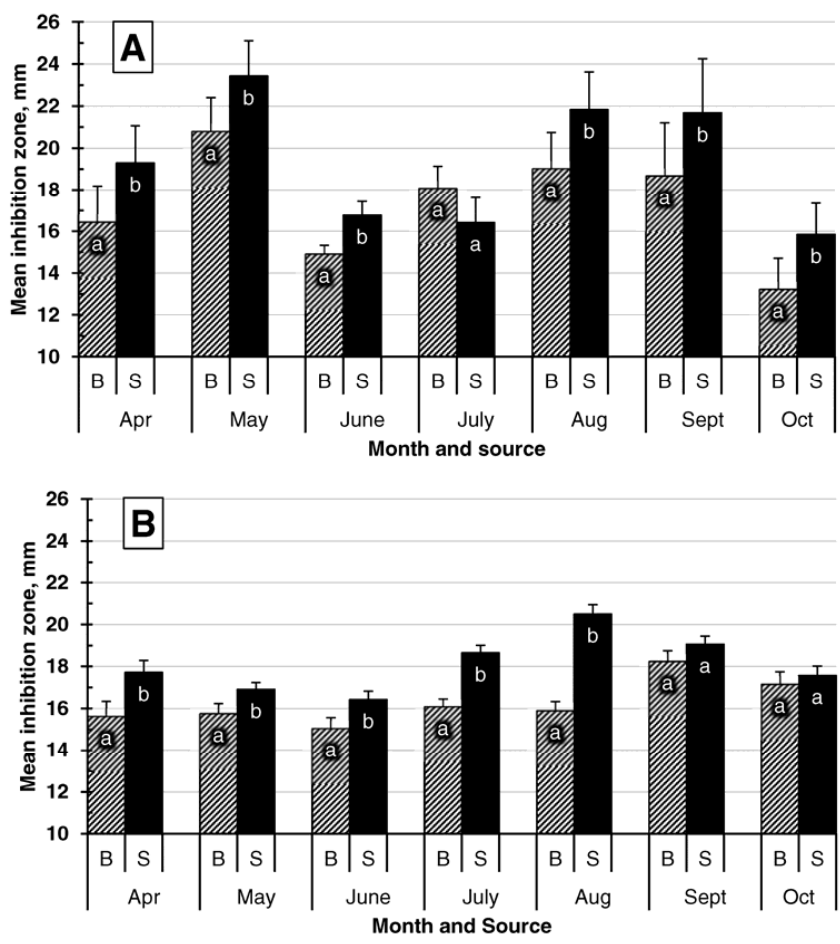

Fig. 3. Inhibition of $\mathrm{Oc}-\mathrm{j}$ conidia germination at $72 \mathrm{~h}$ using a bark extract disc assay, by tree source and month of bark collection. A, 2006; B, 2010. Data points are mean diameters of inhibition zones, combining isolate and bark age. $B=$ unselected butternut $(n=5), S=$ selected butternut $(n=2)$. Values with the same letter do not differ significantly according to ANOVA $(P<0.05)$. Bars represent standard error. both juglone and plumbagin standard compounds in time of elution and observed mass. Juglone peaks had a mass of $175 \mathrm{Da}$ and a time of elution approximately $5.5 \mathrm{~min}$, and plumbagin peaks had a mass of $189 \mathrm{Da}$ and a time of elution approximately $4.5 \mathrm{~min}$. Trace amounts of 1,4-naphthoquinone may also have been present, but were too low to confirm. Consequently, the remainder of the analyses will focus only on juglone and plumbagin.

Juglone concentrations in 2010 varied from a low of $0.14 \mathrm{mM}$ (W01, August) to a high of $2.32 \mathrm{mM}$ (S48, April). Juglone concentrations in 2011 varied from $0.67 \mathrm{mM}$ (S39, August) to $2.2 \mathrm{mM}$ (Y165, August). Plumbagin concentrations were generally 10-fold
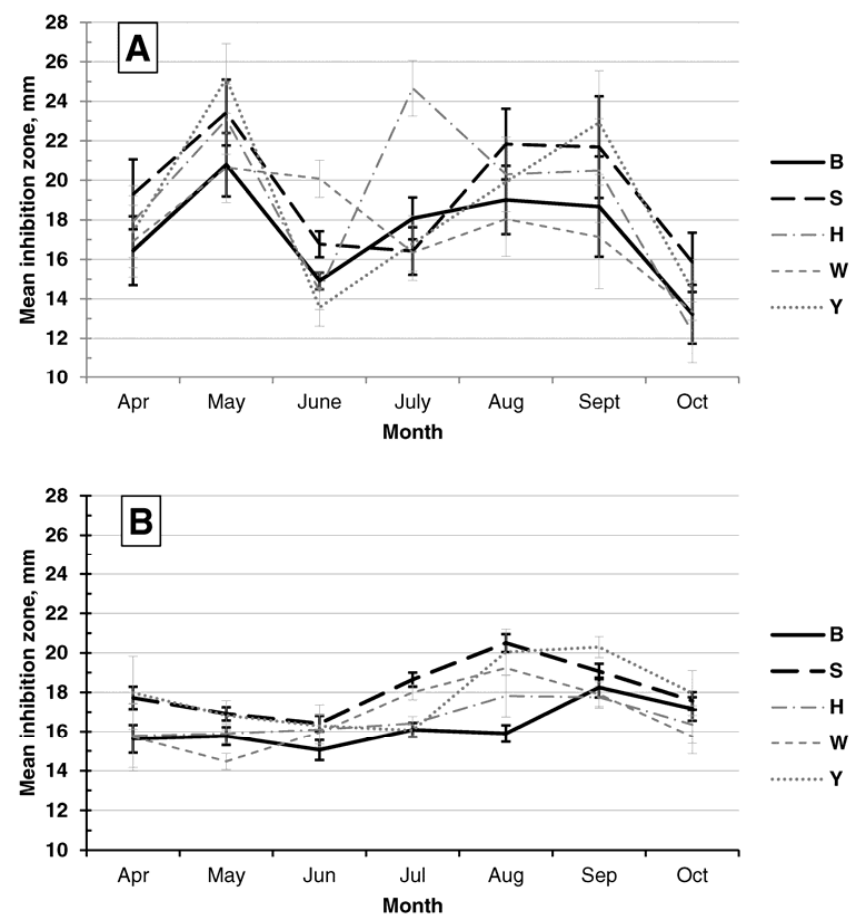

Fig. 4. Inhibition of $0 c-j$ conidia germination at $72 \mathrm{~h}$ using a bark extract disc assay, comparing month of bark collection and source. A, 2006; B, 2010. Data points are mean diameters of inhibition zones. $B=$ unselected butternut, $S=$ selected butternut, $\mathrm{H}=$ heartnut, $\mathrm{W}=$ black walnut, $\mathrm{Y}=$ hybrid. Bars represent standard error.
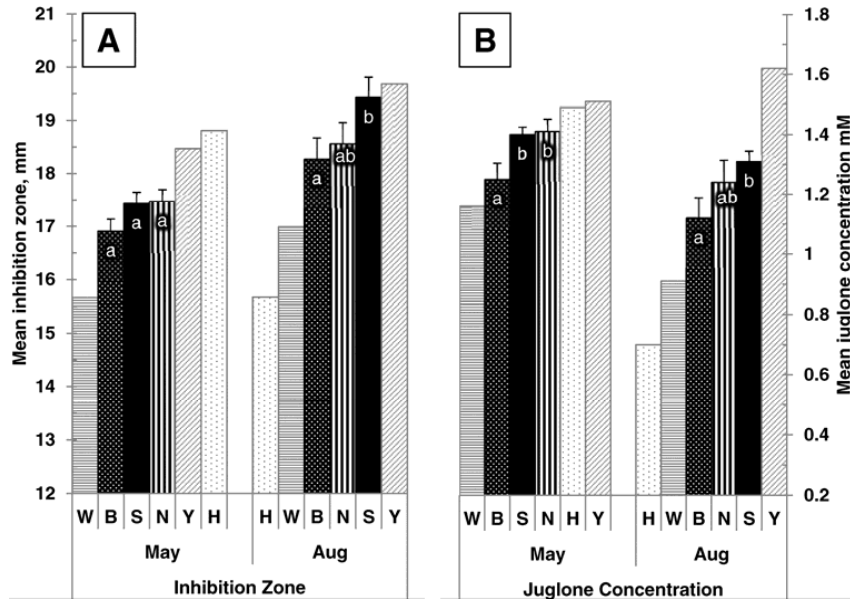

Fig. 5. Inhibition of $0 c-j$ conidia germination at $72 \mathrm{~h}$ using a bark extract disc assay in 2011 (A), compared to juglone concentration of the same extracts (B), by tree source and month of bark collection. Values are means of three replications. $B=$ unselected butternut $(n=10), \mathrm{N}=$ named variety $(n=11), S=$ selected butternut $(n$ $=43$ ). Values with the same letter do not differ significantly according to Fisher's $\operatorname{LSD}(P<0.05)$. Separate analyses were performed for each response variable. Included for comparison, but not in statistical analysis due to limited data: $\mathrm{H}=$ heartnut, $W=$ black walnut, $Y=$ hybrid (heartnut $\times$ butternut). Bars represent standard error. 
lower; in 2010 they varied from a low of $0.018 \mathrm{mM}$ (Y28, August) to a high of $0.27 \mathrm{mM}$ (S54, July). In 2011 they varied from 0.13 $\mathrm{mM}$ (S67, August) to $0.82 \mathrm{mM}$ (S19, August).

Comparison of juglone and plumbagin concentrations in 2010. Overall juglone levels were highest in April (mean of 1.60 $\mathrm{mM}$ ) and decreased until August (mean of $0.31 \mathrm{mM}$ ), then increased again in the fall (Fig. 6). By accession, the lowest juglone levels were found in B16 (mean $0.65 \mathrm{mM}$, months combined) and highest in S20 (mean $0.97 \mathrm{mM}$, months combined). The concentration of juglone varied significantly by both month and accession $(P$ $<0.0001)$. Concentrations in April and August were significantly different from all other months $(P<0.0001)$. There were significant differences in juglone concentrations between accessions in every month but May and September $(P<0.0001)$. When analyzed by selection group, selected butternuts were significantly higher in juglone concentration than unselected butternuts in April, July, and August (Fig. 7).

Plumbagin concentrations also varied by month and accession. They were highest in 2010 in May, June, and July (mean 0.17 $\mathrm{mM}$ ), lowest in August (mean $0.033 \mathrm{mM}$ ), then increased slightly in the fall (Fig. 6). There were significant differences between seasons, with May to July significantly higher than August to October. Variation by accession (months combined) ranged from a mean of $0.086 \mathrm{mM}$ in $\mathrm{W} 01$ to $0.13 \mathrm{mM}$ in $\mathrm{H} 133$, with significant differences between individual accessions for each month (data not shown). When analyzed by selection and species, no clear pattern emerged (data not shown).

Comparison of juglone and plumbagin concentrations in 2011. Extracts from bark collected in May were significantly higher in juglone and plumbagin concentrations than from bark collected in August, similar to the 2010 data. Conversely, activity of the bioassay was higher in August and lower in May. Juglone levels showed variation by tree selection, with selected butternut significantly higher in juglone than unselected butternut in both months (Fig. 5). Named varieties were not significantly different from selected butternuts in either month. Ranking and separation patterns were very similar between the bioassay and the juglone data in regards to tree source in 2011. When juglone concentrations were compared by accession, ranking of accessions and mean separations were relatively similar to the bioassay data (Supplementary Figure 2). Plumbagin concentrations did not vary significantly by selected versus unselected, nor did they follow a pattern similar to either juglone concentrations.

Comparison of juglone and plumbagin concentrations with bioassay results. Extracts collected in several months showed a strong linear correlation between conidial germination inhibition levels and juglone concentration of individual extracts (Table 3). In July, June, and April of 2010, the P-values were $<0.0001,0.001$, and 0.002 , respectively. In 2011, P-values were $<0.0001$ for both the May and August bark collections. When the bioassay data was compared with plumbagin concentration, the correlations were not as strong. The only significant $(P=0.036)$ linear correlation in either year was in April 2010.

\section{Discussion}

Restoration of butternut will require a reliable procedure to select trees that have resistance to butternut canker. Some success has been reported by investigators challenging trees directly with the pathogen in common garden orchards, where a statistically significant separation was found between selected and unselected trees (27). However, propagating candidate trees, establishing orchards, and testing trees in this manner is time- and cost-prohibitive in most cases. We need a rapid, repeatable test that distinguishes highly disease resistant trees from susceptible trees. The bark extract bioassay yielded a statistically significant difference in inhibition of $O c-j$ conidia germination among selected butternuts when compared to unselected butternuts in some months. Results of the bioassay produced resistance rankings of trees similar to screening orchard trees in the field by challenging them with the fungus us-

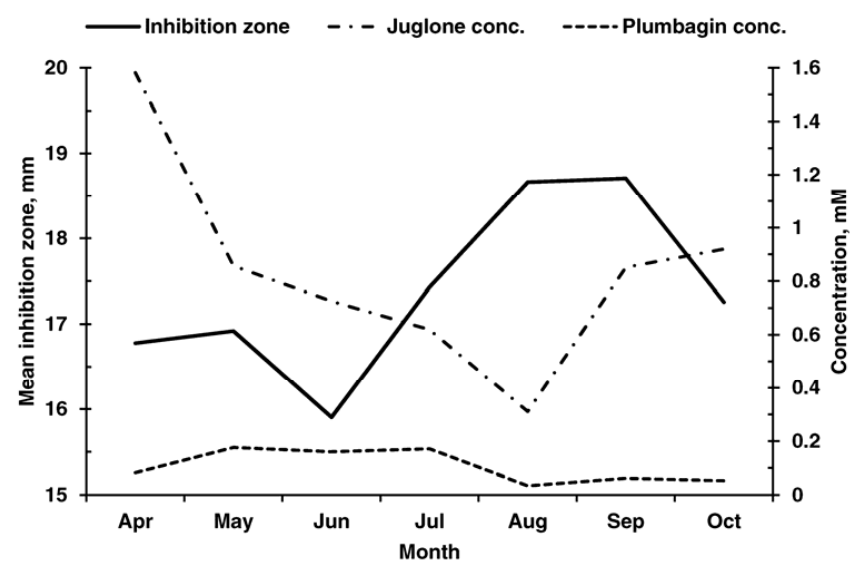

Fig. 6. Inhibition of $O c-j$ conidia germination at $72 \mathrm{~h}$ using a bark extract disc assay (mean diameter of inhibition zone) by month of bark collection compared to mean juglone and plumbagin concentrations of the same bark extracts, 2010.

Table 2. Inhibition of $O c-j$ conidia germination at 72 hours using a bark extract disc assay with bark collected in August in each of three years. Accessions listed are those used in the assay in two or three years

\begin{tabular}{|c|c|c|c|c|c|c|c|c|}
\hline \multicolumn{3}{|c|}{$2006^{w}$} & \multicolumn{3}{|c|}{$2010^{x}$} & \multicolumn{3}{|c|}{$2011^{x}$} \\
\hline \multirow[b]{2}{*}{ Accession } & \multicolumn{2}{|c|}{ Inhibition zone, $\mathrm{mm}$} & \multirow[b]{2}{*}{ Accession } & \multicolumn{2}{|c|}{ Inhibition zone, $\mathbf{m m}$} & \multirow[b]{2}{*}{ Accession } & \multicolumn{2}{|c|}{ Inhibition zone, mm } \\
\hline & Mean diameter ${ }^{y}$ & SE & & Mean diameter ${ }^{y}$ & SE & & Mean diameter $^{y}$ & SE \\
\hline $\mathrm{B} 16$ & $14.0 \mathrm{a}$ & 0.74 & B16 & $14.9 \mathrm{a}$ & 0.79 & B16 & $15.2 \mathrm{a}$ & 0.59 \\
\hline W01 & $18.0 \mathrm{~b}$ & 0.67 & B10 & $15.7 \mathrm{a}$ & 0.89 & H133 & $15.7 \mathrm{ab}$ & 0.27 \\
\hline B03 & $18.2 \mathrm{~b}$ & 0.84 & B04 & $16.0 \mathrm{ab}$ & 1.25 & $\mathrm{~S} 54^{\mathrm{z}}$ & $15.9 \mathrm{ab}$ & 0.40 \\
\hline B04 & $19.9 \mathrm{c}$ & 0.87 & B03 & $16.1 \mathrm{ab}$ & 1.26 & $\mathrm{~S} 60^{\mathrm{z}}$ & $16.7 \mathrm{abc}$ & 0.25 \\
\hline Y128 & $19.9 \mathrm{c}$ & 0.54 & B11 & $16.8 \mathrm{abc}$ & 0.98 & B03 & $16.9 \mathrm{abc}$ & 0.08 \\
\hline $\mathrm{H} 133$ & $20.3 \mathrm{c}$ & 0.57 & H133 & $17.8 \mathrm{abcd}$ & 1.07 & W01 & $17.1 \mathrm{bc}$ & 0.72 \\
\hline B11 & $20.3 \mathrm{c}$ & 0.73 & $\mathrm{~S} 148^{\mathrm{z}}$ & 19.1 bcde & 0.95 & $\mathrm{~S} 148^{\mathrm{z}}$ & $17.9 \mathrm{~cd}$ & 0.64 \\
\hline $\mathrm{S} 148^{\mathrm{z}}$ & $20.9 \mathrm{c}$ & 0.70 & W01 & 19.2 bcde & 1.21 & Y128 & $18.0 \mathrm{~cd}$ & 0.57 \\
\hline B10 & $22.7 \mathrm{~d}$ & 0.83 & $\mathrm{~S} 54^{\mathrm{z}}$ & $19.5 \mathrm{cde}$ & 0.97 & B10 & $18.4 \mathrm{~cd}$ & 0.62 \\
\hline \multirow[t]{6}{*}{$\mathrm{S} 22^{\mathrm{z}}$} & $22.8 \mathrm{~d}$ & 0.93 & $\mathrm{~S} 01^{\mathrm{z}}$ & $19.6 \mathrm{cde}$ & 1.21 & S20 & $19.4 \mathrm{de}$ & 0.69 \\
\hline & & & Y128 & $20.0 \mathrm{de}$ & 1.17 & $\mathrm{~S} 22^{\mathrm{z}}$ & $19.4 \mathrm{de}$ & 0.36 \\
\hline & & & $\mathrm{S} 22^{\mathrm{z}}$ & $20.3 \mathrm{de}$ & 0.93 & $\mathrm{~S} 01^{\mathrm{z}}$ & $20.7 \mathrm{e}$ & 0.90 \\
\hline & & & $\mathrm{S} 20$ & $20.7 \mathrm{de}$ & 1.26 & B11 & $20.9 \mathrm{e}$ & 0.97 \\
\hline & & & $\mathrm{S} 60^{\mathrm{z}}$ & $22.0 \mathrm{e}$ & 1.46 & S67z & $23.8 \mathrm{f}$ & 0.58 \\
\hline & & & S67z & $22.3 \mathrm{e}$ & 1.23 & B04 & $23.8 \mathrm{f}$ & 0.40 \\
\hline
\end{tabular}

\footnotetext{
${ }^{\mathrm{w}}$ Data combined from 1- to 4-year-old bark, two separate isolates and two replications.

${ }^{x}$ Data from four mixed isolates and three replications.

y Values with the same letter do not differ significantly according to Fisher's LSD test $(P<0.05)$.

z Trees that performed in the upper $25 \%$ of the ranking for either least canker incidence or smallest cankers in a field test (27).
} 
ing traditional inoculation techniques (27). The trees that performed in the upper $25 \%$ of the ranking for either least canker incidence or smallest cankers in the field test also tended to rank well for largest inhibition zones in the bioassay (Table 2).

The original extraction procedure and method of storage in 2006 may have resulted in inconsistencies of data between extracts and between replications. For example, the measured inhibition zones of the extracts were more variable between months and between sources in 2006 than 2010 (Fig. 4). When the procedure was modified to produce less heat during the tissue grinding and extraction process, the measured inhibition zone was less variable. Also, replication one was consistently higher than replication two in 2006, possibly pointing to chemical degradation between timing of experiments. When extracts were stored at $-70^{\circ} \mathrm{C}$ rather than $-20^{\circ} \mathrm{C}$, in 2010 and 2011, variation between replications was less variable.

Chemical profiles of butternut bark may vary by age. Extracts from current year's bark were less inhibitory than extracts from older bark. Past greenhouse inoculations of young plants with $O c-j$ have demonstrated the ability of the fungus to colonize young tissues of not only butternut but also species not normally susceptible in the field (25). In addition, initial infections by $O c$-j commonly occur on young (current to 1-year-old) branches in the crowns of trees (32), also suggesting that bark age may be a factor in the chemical inhibition of the fungus.

The chemical analysis confirmed the presence of both juglone and plumbagin in the bark extracts. Plumbagin had not previously been confirmed in $J$. cinerea. Concentrations of plumbagin in butternut bark tissue was generally 10-fold less than juglone, and did not follow the same monthly concentration pattern. Although plumbagin performed strongly in the naphthoquinone assay, measured plumbagin concentrations correlated poorly with the bark extract bioassay so its potential role in canker resistance cannot be inferred.

Juglone concentration and bioassay ranking of tree accessions were closely correlated in 2011 (Table 3). However, in 2010 the juglone levels correlated with the bioassay in bark collection from only three months and the monthly concentration of juglone and the bioassay results varied widely (Fig. 6). The strong inhibition effect by bark extracts collected in August of 2010, despite low levels of juglone and plumbagin, suggests that other bark chemicals may be also responsible for inhibiting the germination of $O c-j$ conidia, and merits further study.

Chemical concentrations in plant extracts can fluctuate throughout the growing season. A variety of phenolics, flavonoids, and quinones in walnut ( $\mathrm{J}$. regia) leaves were shown to vary by time of collection (30). In that study, juglone concentration was relatively low at the end of May and increased to a peak in mid-July. In our study, we also detected differences in the bioassay and the juglone and plumbagin concentrations depending on month of bark collec-

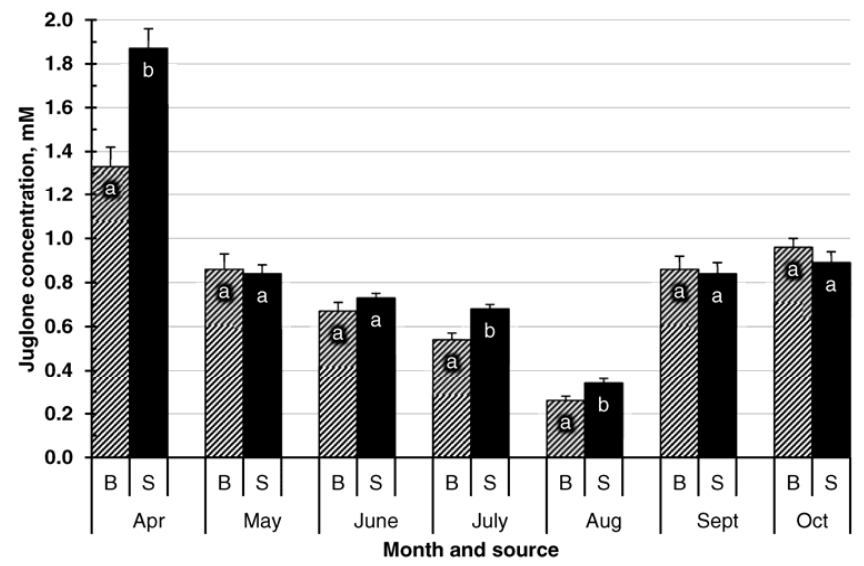

Fig. 7. Juglone concentration of bark extracts in 2010, by tree source and month of bark collection. $\mathrm{B}=$ unselected butternut $(n=5), \mathrm{S}=$ selected butternut $(n=7)$, mean of three replications. Values with the same letter do not differ significantly according to ANOVA $(P<0.05)$. Bars represent standard error. tion. In addition, yearly and monthly differences in concentrations of bark chemicals may be influenced by phenology. If so, timing of bark collection would need to be carefully considered if an extract screening test were to be implemented. In the three years of the study, the greatest distinction between selected and unselected trees was found with extracts from bark collected in August. In addition, individual tree accessions ranked similarly in the bioassay using bark collected in August. August was also the month with the smallest cankers produced by artificial inoculations of trees with the fungus (27). This suggests that this may be a key period for butternut trees to produce active defense compounds. However, both juglone and plumbagin concentrations varied widely from July to August of 2010 (Fig. 6); therefore, collection timing may be critical, and further study is warranted.

In past studies, black walnut, heartnut, and buart (hybrid butternut) trees have been observed to be more resistant to $O c-j$ than butternut $(14,25)$. We expected that bark extracts of these species would result in larger inhibition zones and/or higher concentrations of juglone and/or other naphthoquinones than butternut in the studies described here. The hybrid bark extract was often moderately high in inhibition and in juglone concentration compared to the butternuts, but black walnut and heartnut extracts often had moderate to low levels of inhibition and juglone concentration, suggesting that different resistance mechanisms are present in these two species than in butternut. For example, they may have a different chemical profile and/or physical structures that provide a barrier to the fungus. In addition, the data for these studies was taken from only one or two black walnut trees and one heartnut tree, complicating broad inferences made about the species as a whole.

The assumption of this research was that juglone and/or other naphthoquinones were present constitutively as a consistent baseline for comparison among tree accessions. Research in other pathosystems has revealed defensive substances that are induced when the tree is wounded or under attack by a pathogen or herbivore. Classic examples of these are the stilbenes that are synthesized when Scots pine is infected by Heterobasidion. These stilbenes are correlated with higher decay resistance (16). If production of juglone or other substances in the bark extract were influenced by wounding or the presence of active $O c-j$ cankers, the interpretation of the bioassay and the chemical analysis could be very different. Although all the trees used were free of obvious cankers, several collections revealed staining and/or small incipient cankers during the bark peeling process. The presence of trees with undetected cankers in the bark collections could be influencing the outcomes of both the bioassay and the chemical analysis. A possible next step in this research would involve comparing bark samples from healthy versus cankered trees to see if the bioassay and/or chemical analyses differ, or to track chemical changes after inoculation and/or wounding. With refinement, a bark extract bioassay could be a reasonable screening technique and significantly shorten the time needed to evaluate butternut trees for resistance to butternut canker.

Table 3. Linear regression statistics between bioassay data (mean diameter of inhibition zone) and juglone concentration $(\mathrm{mM})$ for each extract, for 2010 and 2011, listed by month of bark collection. All study trees are included

\begin{tabular}{lcc}
\hline Collection month & $\begin{array}{c}\text { Coefficient of determination } \\
\text { (adjusted } \boldsymbol{R}^{\mathbf{2}} \text { ) }\end{array}$ & $\boldsymbol{P}$-value \\
\hline 2010 & & \\
April & 0.498 & 0.002 \\
May & 0.013 & 0.295 \\
June & 0.543 & 0.001 \\
July & 0.835 & $<0.0001$ \\
August & -0.076 & 0.908 \\
September & -0.010 & 0.371 \\
October & -0.073 & 0.824 \\
2011 & & \\
May & 0.584 & $<0.0001$ \\
August & 0.578 & $<0.0001$ \\
\hline
\end{tabular}




\section{Literature Cited}

1. Anonymous. 1967. Forest pest conditions in Wisconsin. Wisconsin Conservation Department, Wisconsin Department of Natural Resources, Madison, WI.

2. Baiocchi, C., Marengo, E., Roggero, M. A., Giacosa, D., Vietto, L., and Toccori, S. 1994. A chromatographic and chemometric study of the bark phenolic compounds of two poplar clones with different resistance to Discosporium populeum. Chromatographia 39:482-489.

3. Barry, A. L. 1964. The routine antibiotic disc-plate sensitivity tests. I. Variations in the size of inoculum. Am. J. Med. Technology (May-June 1964): 153-161.

4. Binder, R. G., Benson, M. E., and Flath, R. A. 1989. Eight 1,4-naphthoquinones from Juglans. Phytochemistry 28:2799-2801.

5. Broders, K. D., and Boland, G. J. 2011. Reclassification of the butternut canker fungus, Sirococcus clavigignenti-juglandacearum, into the genus Ophiognomonia. Fungal Biol. 115:70-79.

6. Cline, S., and Neely, D. 1984. Relationship between juvenile-leaf resistance to anthracnose and the presence of juglone and hydrojuglone glucoside in black walnut. Phytopathology 74:185-188.

7. Curreli, N., Sollai, F., Massa, L., Comandini, O., Rufo, A., Sanjust, E., Rinaldi, A., and Rinaldi, A. C. 2001. Effects of plant-derived naphthoquinones on the growth of Pleurotus sajor-caju and degradation of the compounds by fungal cultures. J. Basic Microbiol. 41:253-259.

8. Davis, E. F. 1928. The toxic principle of Juglans nigra as identified with synthetic juglone, and its toxic effects on tomato and alfalfa plants. Am. J. Bot. 15:620.

9. Ficker, C. E., Arnason, J. T., Vindas, P. S., Alvarez, L. P., Akpagena, K., Gbeassor, M., De Souza, C., and Smith, M. L. 2003. Inhibition of human pathogenic fungi by ethnobotanically selected plant extracts. Mycoses 46:29-37.

10. Hadacek, F., and Greger, H. 2000. Testing of antifungal natural products: methodologies, comparability of results and assay choice. Phytochemical Analysis 11:137-147.

11. Hedin, P. A., Langhans, V. E., and Graves, C. H., Jr. 1979. Identification of juglone in pecan as a possible factor of resistance to Fusicladium effusum. J. Agric. Food Chem. 27:92-94.

12. Heimann, M. F., and Stevenson, W. R. 1997. Walnut and butternut toxicity. Urban Phytonarian Series. University of Wisconsin-Extension.

13. Hjalten, J., Niemi, L., Wennstrom, A., Ericson, L., Roininen, H., and Julkunen-Tiitto, R. 2007. Variable responses of natural enemies to Salix triandra phenotypes with different secondary chemistry. Oikos 116:751-758.

14. Hoban, S. 2008. Butternuts, hybrids, and butternut canker: current and future research. The Nutshell (December 2008):14-16.

15. Hoban, S. M., McCleary, T. S., Schlarbaum, S. E., and Romero-Severson, J. 2009. Geographically extensive hybridization between the forest trees American butternut and Japanese walnut. Biol. Lett. 5:324-327.

16. Kovalchuk, A., Kerio, S., Oghenekaro, A., Jaber, E., Raffaello, T., and Asiegbu, F. 2013. Antimicrobial defenses and resistance in forest trees: Challenges and perspectives in a genomics era. Annu. Rev. Phytopathol. 51:221-244.

17. Krajci, W. M., and Lynch, D. L. 1978. The inhibition of various micro- organisms by crude walnut hull extracts and juglone. Microbios Lett. 4:175-181.

18. Lieutier, F., Brignolas, F., Sauvard, D., Yart, A., Galet, C., Brunet, M., and Van De Sype, H. 2003. Intra- and inter-provenance variability in phloem phenols of Picea abies and relationship to a bark beetle-associated fungus. Tree Physiol. 23:247-256.

19. Mahoney, N., Molyneux, R. J., and Campbell, B. C. 2000. Regulation of aflatoxin production by naphthoquinones of walnut (Juglans regia). J. Agric. Food Chem. 48:4418-4421.

20. Massey, A. B. 1925. Antagonism of the walnuts (Juglans nigra L. and J. cinerea L.) in certain plant associations. Phytopathology 15:773-784.

21. Michler, C. H., Pijut, P. M., Jacobs, D. F., Meilan, R., Woeste, K., and Ostry, M. E. 2005. Improving disease resistance of butternut (Juglans cinerea), a threatened fine hardwood: a case for single-tree selection through genetic improvement and deployment. Tree Physiol. 26:121-128.

22. Nair, V. M. G. 1999. Butternut canker - an international concern. Pages 239 252 in: S. P. Raychaudhuri, and K. Maramorosch eds. Biotechnology and Plant Protection in Forestry Science. Oxford \& IBH Publishing Co. Pvt. Ltd., New Delhi.

23. Neamatallah, A., Yan, L., Dewar, S. J., and Austin, B. 2005. An extract from teak (Tectona grandis) bark inhibited Listeria monocytogenes and methicillin resistant Staphylococcus aureus. Lett. Appl. Microbiol. 41:94-96.

24. Omar, S., Lemonier, B., Jones, N., Ficker, C., Smith, M. L., Neema, C., Towers, G. H. N., Goel, K., and Arnason, J. T. 2000. Antimicrobial activity of extracts of eastern North American hardwood trees and relation to traditional medicine. J. Ethnopharmacol. 73:161-170.

25. Orchard, L. P., Kuntz, J. E., and Kessler, K. J., Jr. 1982. Reactions of $J u-$ glans species to butternut canker and implications for disease resistance. Pages 27-31 in: Black Walnut for the Future. U.S. Dep. Agric. For. Serv. North Central For. Exp. Stn., St. Paul, MN.

26. Ostry, M. E., and Moore, M. 2007. Natural and experimental host range of Sirococcus clavigignenti-juglandacearum. Plant Dis. 91:581-584.

27. Ostry, M. E., and Moore, M. 2008. Response of butternut selections to inoculation with Sirococcus clavigignenti-juglandacearum. Plant Dis. 92:1336-1338.

28. Park, B.-S., Kim, J.-R., Lee, S.-E., Kim, K. S., Takeoka, G. R., Ahn, Y.-J., and Kim, J.-H. 2005. Selective growth-inhibiting effects of compounds identified in Tabebuia impetiginosa inner bark on human intestinal bacteria. J. Agric. Food Chem. 53:1152-1157.

29. Park, B.-S., Lee, H.-K., Lee, S.-E., Piao, X.-L., Takeoka, G. R., Wong, R. Y., Ahn, Y.-J., and Kim, J.-H. 2006. Antibacterial activity of Tabebuia impetiginosa Martius ex DC (Taheebo) against Helicobacter pylori. J. Ethnopharmacol. 105:255-262.

30. Solar, A., Colaric, M., Usenik, V., and Stampar, F. 2006. Seasonal variations of selected flavonoids, phenolic acids and quinones in annual shoots of common walnut (Juglans regia L.). Plant Sci. 170:453-461.

31. Solar, A., Jakopic, J., Veberic, R., and Stampar, F. 2012. Correlations between Xanthomonas arboricola pv. juglandis severity and endogenous juglone and phenolic acids in walnut. J. Plant Pathol. 94:229-235.

32. Tisserat, N. A. 1982. Epidemiology of butternut canker. Ph.D. dissertation, University of Wisconsin, Madison, WI.

33. Windham, G., and Graves, J., Clinton H. 1981. Reaction of isolates of Fusicladium effusum to juglone. Phytopathology 71:913. 